\title{
Decrease in Skin Prion-Seeding Activity of Prion-Infected Mice Treated with a Compound Against Human and Animal Prions: a First Possible Biomarker for Prion Therapeutics
}

\author{
Mingxuan Ding ${ }^{1,2} \cdot$ Kenta Teruya ${ }^{3} \cdot$ Weiguanliu Zhang ${ }^{1,2} \cdot$ Hae Weon Lee $^{2} \cdot J_{u e}$ Yuan ${ }^{2} \cdot$ Ayumi Oguma $^{3}$. \\ Aaron Foutz ${ }^{2}$. Manuel V. Camacho ${ }^{2}$ - Marcus Mitchell ${ }^{2}$. Justin J. Greenlee ${ }^{4}$ Q Qingzhong Kong ${ }^{2,5} \cdot$ Katsumi Doh-ura $^{3}$. \\ Li Cui $^{1} \cdot$ Wen-Quan Zou ${ }^{2,5}$ D
}

Received: 21 December 2020 / Accepted: 30 April 2021 / Published online: 13 May 2021

(c) The Author(s) 2021

\begin{abstract}
Previous studies have revealed that the infectious scrapie isoform of prion protein $\left(\mathrm{PrP}^{\mathrm{Sc}}\right)$ harbored in the skin tissue of patients or animals with prion diseases can be amplified and detected through the serial protein misfolding cyclic amplification (sPMCA) or real-time quaking-induced conversion (RT-QuIC) assays. These findings suggest that skin PrP ${ }^{\text {Sc }}$-seeding activity may serve as a biomarker for the diagnosis of prion diseases; however, its utility as a biomarker for prion therapeutics remains largely unknown. Cellulose ethers (CEs, such as TC-5RW), widely used as food and pharmaceutical additives, have recently been shown to prolong the lifespan of prion-infected mice and hamsters. Here we report that in transgenic (Tg) mice expressing hamster cellular prion protein $\left(\mathrm{PrP}^{\mathrm{C}}\right)$ infected with the $263 \mathrm{~K}$ prion, the prion-seeding activity becomes undetectable in the skin tissues of TC-5RW-treated Tg mice by both sPMCA and RT-QuIC assays, whereas such prionseeding activity is readily detectable in the skin of untreated mice. Notably, TC-5RW exhibits an inhibitory effect on the in vitro amplification of $\mathrm{PrP}^{\mathrm{Sc}}$ in both skin and brain tissues by sPMCA and RT-QuIC. Moreover, we reveal that TC-5RW is able to directly decrease protease-resistant $\mathrm{PrP}^{\mathrm{Sc}}$ and inhibit the seeding activity of $\mathrm{PrP}^{\mathrm{Sc}}$ from chronic wasting disease and various human prion diseases. Our results suggest that the level of prion-seeding activity in the skin may serve as a useful biomarker for assessing the therapeutic efficacy of compounds in a clinical trial of prion diseases and that TC-5RW may have the potential for the prevention/treatment of human prion diseases.
\end{abstract}

Keywords Prions · Prion diseases $\cdot$ Cellulose ethers $\cdot$ Real-time quaking-induced conversion $($ RT-QuIC) $\cdot$ Serial protein misfolding cyclic amplification (sPMCA) $\cdot$ TC-5RW

Katsumi Doh-ura

doh-ura@med.tohoku.ac.jp

Li Cui

chuili1967@126.com

Wen-Quan Zou

wxz6@case.edu

1 Department of Neurology, The First Hospital of Jilin University, Changchun 130021, Jilin Province, China

2 Departments of Pathology and Neurology, Case Western Reserve University School of Medicine, Cleveland, OH 44106, USA
3 Department of Neurochemistry, Tohoku University Graduate School of Medicine, 2-1 Seiryo-machi, Aoba-ku, Sendai, Miyagi 980-8575, Japan

4 Virus and Prion Research Unit, Agricultural Research Service, National Animal Disease Center, USDA, 1920 Dayton Avenue, Ames, IA 50010, USA

5 National Prion Disease Pathology Surveillance Center, Case Western Reserve University School of Medicine, Cleveland, OH 44106, USA 


\section{Introduction}

Prion diseases or transmissible spongiform encephalopathies are a group of neurodegenerative diseases affecting the central nervous system of humans and animals, including Creutzfeldt-Jakob disease (CJD), kuru, fatal familial insomnia (FFI), Gerstmann-Sträussler-Scheinker (GSS) syndrome, and variably protease-sensitive prionopathy (VPSPr) in humans, and scrapie in sheep and goats, bovine spongiform encephalopathy (BSE), and chronic wasting disease (CWD) in elk and deer [1]. They have a long incubation period and a $100 \%$ fatality rate. All these diseases have detectable deposition in the brain of abnormal infectious misfolded prion protein $\left(\mathrm{PrP}^{\mathrm{Sc}}\right)$, a molecular hallmark of prion diseases, which is derived from its normal cellular prion protein $\left(\mathrm{PrP}^{\mathrm{C}}\right)$ through a structural transition [2].

Our previous study revealed that autopsy skin tissues from sporadic CJD cadavers harbor $\operatorname{PrP}^{\mathrm{Sc}}$ that exhibited seeding activity and infectivity [3] that has recently been confirmed not only with autopsy skin samples from CJD cadavers diagnosed neuropathologically but also biopsy skin samples from living CJD patients [4]. Moreover, in animal models including $263 \mathrm{~K}$ scrapie prion-infected hamsters and sporadic CJD (sCJD) prion-infected humanized transgenic ( $\mathrm{Tg}$ ) mice expressing human wild-type $\mathrm{PrP}$, we further observed that skin $\operatorname{PrP}^{\mathrm{Sc}}$ was detectable by realtime quaking-induced conversion (RT-QuIC) and serial protein misfolding cyclic amplification (sPMCA) assays long before clinical signs and brain lesions manifested [5]. These observations provide the proof-of-concept that skin $\mathrm{PrP}^{\mathrm{Sc}}$ may be a biomarker for early preclinical diagnosis of prion diseases. However, it is unclear whether the level of prion-seeding activity in the skin can serve as a biomarker for assessing the efficacy of anti-prion therapeutics.

Cellulose ethers (CEs), a family of non-digestible, nonionic, and water-soluble polysaccharide derivatives, are widely used as additives in food, pharmaceutical tablets, and personal care products [6, 7]. Doh-ura and co-workers first discovered that CEs including TC-5RW have a significant protective effect on prion infection of animals that were given before and after inoculation [8]. Other teams have also confirmed that this compound can prolong the survival of infected rodents expressing elk or deer PrP infected with different CWD prions [9, 10]. Moreover, a liposomal formulation of CEs was found successfully to lower the effective dose of CE in prion-infected cells [11].

In the present study, we investigate prion-seeding activity in skin samples from prion-infected $\mathrm{Tg}$ mice with or without TC-5RW treatment via RT-QuIC and sPMCA assays. We find that the prion-seeding activity in the skin of TC-5RW-treated mice becomes undetectable but remains detectable in vehicle-treated control mice. Moreover, we reveal that TC-5RW inhibits the amplification of hamster $\mathrm{PrP}^{\mathrm{Sc}}$ from skin and brain tissues in RT-QuIC and sPMCA experiments. Additionally, our RT-QuIC assay reveals that TC-5RW is able to inhibit the seeding activity of $\mathrm{PrP}^{\mathrm{Sc}}$ from CWD and various human prion diseases as well. Finally, in vitro direct incubation of TC-5RW with brain homogenates from hamster, elk, deer, or humans infected by various prions is found to decrease the levels of protease-resistant $\operatorname{PrP}^{\mathrm{Sc}}\left(\mathrm{PrP}^{\text {res }}\right)$.

\section{Materials and Methods}

\section{Reagents and Antibodies}

TC-5RW was kindly provided by Shin-Etsu Chemical Co., Ltd. (Tokyo, Japan). Proteinase K (PK) was purchased from Sigma ALDRICH Co. (St. Louis, MO, USA). Protease inhibition cocktail tablets were purchased from Roche Diagnostics (Indianapolis, IN, USA). Reagents for enhanced chemiluminescence (ECL Plus) were from Thermo Scientific (Rockford, IL, USA). Anti-PrP mouse monoclonal antibody $3 F 4[12,13]$ and sheep anti-mouse IgG conjugated with horseradish peroxidase as a secondary antibody were purchased from Sigma Aldrich [14].

\section{Animal Study}

The animal experiment was performed following a protocol reviewed and approved by the Institutional Animal Care and Use Committee of Tohoku University (approval number 2016MdA-139). Thirteen hemizygous $\mathrm{Tg} 7$ mice at 6 to 10 weeks old obtained by a cross between $\mathrm{Tg} 7$ [15] and PrPnull mice [16] were inoculated intracerebrally with $20 \mu \mathrm{L}$ of $1 \%(\mathrm{w} / \mathrm{v})$ brain homogenate obtained from a terminally ill $263 \mathrm{~K}$ prion-infected hamster. On the day of inoculation, 8 mice were also injected with a single intraperitoneal injection of $1 \mathrm{~mL}$ of $50 \mathrm{mg} / \mathrm{mL}$ TC-5RW in saline, and the other 5 mice were inoculated with $1 \mathrm{~mL}$ of saline as vehicle-treated controls. Mice were monitored daily from inoculation until the terminal stage, at which time the mice exhibited akinesia (with a lack of grooming behavior, coordination, and parachute reaction) or exhibited a rigid tail, an arched back, and weight loss of approximately $10 \%$ within 1 week [17]. The mice were sacrificed at the terminal stage. The time from inoculation to death was defined as the survival time. Skin samples from the back near the tail and brain samples were taken immediately after sacrifice as described previously [5]. The scissors and tweezers used for skin collection were handled with great care to avoid contamination from the brain to the skin or between mice. The skin samples were collected first before opening the skull for collecting brain tissues and 
all devices were decontaminated after each use. The skin tissues were frozen on dry ice and stored in a $-80{ }^{\circ} \mathrm{C}$ freezer for future use. Some of the brain samples were similarly frozen and kept in a freezer, while some were formalin fixed and paraffin embedded as described previously [18].

\section{Paraffin-Embedded Tissue Blotting and Hematoxylin/Eosin Staining}

Paraffin-embedded tissue (PET) blot analysis was performed for detection of $\mathrm{PrP}^{\mathrm{Sc}}$ deposition in the brain as described previously [18]. In brief, $6-\mu \mathrm{m}$ paraffin-embedded brain sections were cut and collected onto nitrocellulose membranes and then dried overnight at $60{ }^{\circ} \mathrm{C}$. Membranes were dewaxed in xylene, followed by step-wise rehydration. After wetting with Tris-buffered saline-tween 20 (TBST) (10 mM Tris-HCl, pH 7.8, $100 \mathrm{mM} \mathrm{NaCl}$, and $0.05 \%$ Tween-20), sections were digested with $250 \mu \mathrm{g} / \mathrm{mL}$ PK in a buffer (10 mM Tris- $\mathrm{HCl}, \mathrm{pH} 7.8,100 \mathrm{mM} \mathrm{NaCl}$, and 0.1\% Brij35) overnight at $55^{\circ} \mathrm{C}$. After washing with TBST, sections were treated with $3 \mathrm{M}$ guanidine isothiocyanate for $30 \mathrm{~min}$. After washing out guanidine using TBST, immunodetection was performed with an anti-PrP-C antibody, which recognizes residues 214-228 of mouse/hamster PrP (1:1500, ImmunoBiological Laboratories Co., Ltd., Gunma, Japan). The 3- $\mu \mathrm{m}$ paraffin-embedded brain sections serially adjacent to those used for PET blot analysis were stained with hematoxylin and eosin (H\&E). Assessment of pathological changes including spongiform degeneration was conducted under a light microscope.

\section{Preparation of Brain and Skin Samples}

Skin samples $(\sim 50 \mathrm{mg}$ each in weight, $\sim 5 \mathrm{~mm} \times 5 \mathrm{~mm}$ each in size) were taken with epidermis, dermis, and hypodermis three layers as described previously [5]. They were washed three times in $1 \times$ Tris-buffered saline (TBS) to remove possible blood contamination and cut into small pieces in dishes. The 5\% (w/v) skin homogenates were prepared in skin lysis buffer containing $10 \mathrm{mM}$ Tris-HCl, $133 \mathrm{mM}$ $\mathrm{NaCl}, 2 \mathrm{mM} \mathrm{CaCl} 2$, and $0.25 \%$ collagenase A (Roche), $\mathrm{pH}$ 7.4 , and incubated in a shaker at $37^{\circ} \mathrm{C}$ for $4 \mathrm{~h}$. Mouse brain samples at $5 \%(\mathrm{w} / \mathrm{v})$, hamster, and human autopsy brain samples at $10 \%(\mathrm{w} / \mathrm{v})$ were homogenized in lysis buffer containing $125 \mathrm{mM} \mathrm{NaCl}, 12.5 \mathrm{mM}$ EDTA, $12.5 \mathrm{mM}$ Tris- $\mathrm{HCl}$, $0.5 \%$ sodium deoxycholate, $0.5 \%$ NP-40, and $\mathrm{pH} 7.4$, with a Mini-Beadbeater (BioSpec, Laboratory Supply Network, Inc., Atkinson, $\mathrm{NH}$ ) shaking (1 min)-incubating on ice ( 2 min) cycle for 3 cycles. Frozen brain tissues from two white-tailed deer and a reindeer with CWD [19-21] were prepared for $10 \%$ brain homogenate in $2 \%$ Sarkosyl solution.

\section{RT-QuIC Assay}

RT-QuIC assays of skin from $\mathrm{Tg} 7$ mice and brain samples from $263 \mathrm{~K}$-infected hamster, patients with different prion diseases, and CWD deer were performed as previously described [5], with minor modification. In brief, RT-QuIC reaction mix was composed of $1 \times$ phosphate buffer $\mathrm{pH} 7.4$, $0.17 \mathrm{M} \mathrm{NaCl}, 0.1 \mathrm{mg} / \mathrm{mL}$ homemade recombinant truncated Syrian golden hamster PrP90-231 [22], $10 \mu \mathrm{M}$ Thioflavin T (ThT), $1 \mathrm{mM}$ EDTA, and $0.001 \%$ SDS. Each well of a 96-well plate (Nunc) was loaded with $96 \mu \mathrm{L}$ of reaction mix and seeded with $2 \mu \mathrm{L}$ of $\operatorname{Tg} 7$ mouse skin homogenate at a final concentration of $10^{-3}$ or deer or human brain homogenate at a final concentration of $2 \times 10^{-7}$. Seeds were spun at $5000 \times g$ for $2 \mathrm{~min}$ at $4{ }^{\circ} \mathrm{C}$ prior to loading. To investigate the inhibitory effect of TC-5RW on prion-seeding activity in RT-QuIC, $2 \mu \mathrm{L}$ of differing concentrations of TC-5RW was added to reaction wells before loading seeds. The plates were sealed with a plate sealer film (Nalgene Nunc International) and incubated at $55^{\circ} \mathrm{C}$ for skin samples and $42{ }^{\circ} \mathrm{C}$ for brain samples in a BMG FLUOstar Omega plate reader with cycles of 1 min shaking (700 rpm double orbital) and 1-min rest throughout the indicated incubation time. ThT fluorescence intensity $(450 \pm 10-\mathrm{nm}$ excitation and 480 $\pm 10-\mathrm{nm}$ emissions; bottom read) was measured every $45 \mathrm{~min}$. All samples were run in quadruplicate. The average fluorescence of each sample was determined by taking the average of all four replicates regardless of whether their ThT values were above the threshold described below. Samples with at least 2 out of 4 replicate wells above the determined threshold were considered positive. A ThT fluorescence threshold for a reaction to define the positive and negative cases was determined based on the mean ThT value of all negative control samples at $60 \mathrm{~h}$, plus 3 standard deviations as previously described [5]. For comparison, the average ThT fluorescence was normalized as percentages with the highest fluorescence in each plate. The differences in prion-seeding activity may result in variable lag phase or lag time of prion aggregation, the time point when the ThT fluorescence of protein aggregates RT-QuIC starts to continuously increase [10]. So, the lag time of the RT-QuIC reaction was also used to compare prion-seeding activity among different prion diseases in our study.

\section{Serial PMCA Analysis}

Serial PMCA (sPMCA) assay as well as the preparation of $\mathrm{PrP}^{\mathrm{Sc}}$ seeds and $\mathrm{PrP}^{\mathrm{C}}$ substrates were conducted as previously described [5, 23, 24] with minor modification. Briefly, to make the sPMCA $\operatorname{PrP}^{\mathrm{C}}$ substrate, normal hamster or humanized $\mathrm{Tg}$ mouse brain tissues expressing human wild-type PrP (Tg40h) [13] were carefully dissected to avoid blood contamination as much as possible. 
The normal hamster or humanized Tg mouse brain tissues were homogenized $(10 \% \mathrm{w} / \mathrm{v})$ in sPMCA conversion buffer containing $150 \mathrm{mM} \mathrm{NaCl}, 1 \%$ Triton X-100, $8 \mathrm{mM}$ EDTA, $\mathrm{pH}$ 7.4, and the complete protease inhibitor mixture cocktail (Roche) in PBS, followed by centrifugation at $1000 \mathrm{~g}$ at $4{ }^{\circ} \mathrm{C}$ for $10 \mathrm{~min}$ to collect the supernatant (S1) fraction. Finally, the supernatant was mixed with $5 \mathrm{mg} / \mathrm{mL}$ heparin at 50:1. The substrates and seeds were kept at $-80{ }^{\circ} \mathrm{C}$ until use. Each skin $\operatorname{PrP}^{\mathrm{Sc}}$ seed was diluted in the substrate at the ratios 1:12.5 (8 $\mu \mathrm{L}$ seed in $100 \mu \mathrm{L}$ mix) into $200 \mu \mathrm{L} \mathrm{PCR}$ tubes with 1 PTFE beads (diameter 3/32") (Teflon, APT, RI) while $263 \mathrm{~K}$-infected hamster brain homogenate seeds or SCJDMM1- or SCJDMM2-infected human brain homogenate seeds were diluted at the ratios 1:100 $(1 \mu \mathrm{L}$ seed in 100 $\mu \mathrm{L}$ mix) as positive controls. To detect the inhibitory effect of TC-5RW of seed activity in sPMCA, $2 \mu \mathrm{L}$ different concentration of TC-5RW was added to the $100 \mu \mathrm{L}$ system. A $20 \mu \mathrm{L}$ of each mixture was taken out and kept at $-20^{\circ} \mathrm{C}$ as a non-PMCA control. The remaining mixtures were subjected to sPMCA. Each cycle comprises a 20-s elapse time of sonication at amplitude 85 ( $250 \mathrm{~W}$; Misonix S4000 sonicator) followed by an incubation period of $29 \mathrm{~min} 40 \mathrm{~s}$ at $37{ }^{\circ} \mathrm{C}$ and each round of sPMCA consisted of 80 cycles. For the sPMCA, $15-\mu \mathrm{L}$ sample, each was aliquoted from the last cycle and placed into $65-\mu \mathrm{L}$ fresh normal brain substrates for the next round of amplification.

\section{Incubation of TC-5RW with Brain Homogenates}

Ten percent $(w / v)$ brain homogenates in lysis buffer from patients with different sCJD subtypes or $263 \mathrm{~K}$-infected hamsters were incubated with TC-5RW at final concentrations ranging from $0 \sim 30 \mu \mathrm{g} / \mathrm{mL}$ for $37^{\circ} \mathrm{C}, 400 \mathrm{rpm}$, or kept at $-20^{\circ} \mathrm{C}$ as designated hours. The samples were treated with PK at $100 \mu \mathrm{g} / \mathrm{mL}, 37^{\circ} \mathrm{C}$ for an hour, followed by protease inhibition cocktail and boiled in the SDS sample buffer prior to Western blot analysis probing with the $3 \mathrm{~F} 4$ antibody as shown below.

\section{Two-Dimensional Western Blotting}

Two-dimensional (2D) Western blotting of PrP was performed as previously described [14]. In brief, tissue homogenates were boiled in SDS sample buffer (3\% SDS, 2 mM EDTA, $4 \% \beta$-mercaptoethanol, $10 \%$ glycerol, $50 \mathrm{mM}$ Tris, pH 6.8), followed by precipitation by 5 volumes of prechilled methanol at $-20^{\circ} \mathrm{C}$ for $2 \mathrm{~h}$, then centrifugation at $14,000 \mathrm{rpm}$ for $30 \mathrm{~min}$ at $4{ }^{\circ} \mathrm{C}$. The pellets were resuspended in $50 \mu \mathrm{L}$ reducing buffer ( $8 \mathrm{M}$ urea, $2 \%$ CHAPS, $5 \mathrm{mM}$ tributylphosphine, $20 \mathrm{mM}$ Tris, $\mathrm{pH} \mathrm{8.0)}$ for $1 \mathrm{~h}$ at room temperature (RT), then added $5 \mu \mathrm{L}$ iodoacetimate $(200 \mathrm{mM})$ in dark at RT for more than $1 \mathrm{~h}$. Five volumes of pre-chilled methanol were added and incubated at $-20{ }^{\circ} \mathrm{C}$ for $2 \mathrm{~h}$ and centrifuged at $14,000 \mathrm{rpm}$ for $30 \mathrm{~min}$ at $4{ }^{\circ} \mathrm{C}$. The pellets were resuspended in $200 \mu \mathrm{L}$ of rehydration buffer $(7 \mathrm{M}$ urea, $2 \mathrm{M}$ thiourea, $1 \%$ DTT, $1 \%$ CHAPS, $1 \%$ Triton X-100, $1 \%$ ampholyte $\mathrm{pH} 3-10$, trace of amount bromophenol blue) and centrifuged at $5000 \mathrm{rpm}$ for $5 \mathrm{~min}$ at RT.

The samples were loaded onto the immobilized $\mathrm{pH}$ gradient strips for rehydration at RT for more than $12 \mathrm{~h}$ with gentle shaking. The first-dimensional isoelectric focusing was performed on the rehydrated gel strips for $7 \mathrm{~h}$ using a focusing tray. For the second dimension SDS-PAGE, the focused gel strips were equilibrated for $15 \mathrm{~min}$ each in equilibration buffer A (6 M urea, 2\% SDS, 20\% glycerol, $130 \mathrm{mM}$ dithiothreitol, $0.375 \mathrm{M}$ Tris-HCl, $\mathrm{pH}$ 8.8) and equilibration buffer B (6 M urea, 2\% SDS, 20\% glycerol, $135 \mathrm{mM}$ iodoacetamide, $0.375 \mathrm{M}$ Tris- $\mathrm{HCl}, \mathrm{pH} 8.8$ ), respectively. The equilibrated strips were loaded onto $15 \%$ Bio-Rad Criterion gels at $150 \mathrm{~V}$ for $90 \mathrm{~min}$. The rest steps were the same as described below.

\section{Western Blotting}

To detect the PK-resistant $\operatorname{PrP}\left(\mathrm{PrP}^{\mathrm{res}}\right)$, the samples were incubated with PK at $100 \mu \mathrm{g} / \mathrm{mL}$ at $37{ }^{\circ} \mathrm{C}$ for an hour, shaking at $450 \mathrm{rpm}$, followed by addition of protease inhibitor mixture cocktail (Roche), and boiling at SDS sample buffer for $10 \mathrm{~min}$ in order to terminate the PK reaction, while samples without PK treatment were added to the sample buffer directly to detect untreated PrP. Samples were loaded onto $15 \%$ Tris- $\mathrm{HCl}$ Criterion pre-cast gels (Bio-Rad) for SDS-PAGE. After SDS-PAGE, the proteins on the gels were transferred to Immobilon-P polyvinylidene difluoride (PVDF, Millipore) for $100 \mathrm{~min}$ at $0.35 \mathrm{~A}$. After blocking in TBS-Tween-20 buffer at RT for an hour, the membranes were incubated at RT with anti-PrP antibody $3 \mathrm{~F} 4$ at 1:40,000 dilution overnight. The membranes were washed with washing buffer $(1 \times \mathrm{TBS}, 0.1 \%$ Tween-20) for $5 \mathrm{~min}$ for 4 times, then incubated with horseradish peroxidase-conjugated sheep anti-mouse IgG at 1:3000 dilution at RT for $1 \mathrm{~h}$, followed by washing $5 \mathrm{~min}$ for 4 times. The protein bands were visualized on Kodak film by ECL Plus following the product instruction.

\section{Statistical Analysis}

To quantify the protein level, Western blots were scanned with an Epson Expression 1680 scanner (Epson America, Inc, Los Alamitos, CA). Protein intensity on the Western blots was quantified by densitometric analysis with less exposed films to avoid protein signal saturation and subtracting the background of films using UN-SCAN-IT gel Analysis Software (Silk Scientific, Inc., Orem, UT). The statistical differences in intensity of PrP detected by Western blotting or ThT fluorescence of PrP aggregates among different groups were statistically analyzed 
using Student's $t$-test or one-way ANOVA to obtain $p$ values. All tests adopted a two-sided type I error level of 0.05 .

\section{Results}

\section{TC-5RW-Treated Mice Have Much Longer Survival Time as well as Less PrP ${ }^{S c}$ Deposition and Spongiform Degeneration Than Vehicle-Treated Mice}

Cellulose ethers including TC-5RW are able to extend the survival time of prion-infected rodents $[8,10]$. To determine whether a potential therapeutic effect could be reflected in the prion-seeding activity of skin tissues of infected animals treated with the compound, we intracerebrally inoculated hemizygous $\mathrm{Tg} 7$ mice with the $263 \mathrm{~K}$ prions. On the same day as inoculation, infected $\mathrm{Tg}$ mice were injected intraperitoneally with a single dose of TC-5RW at $50 \mathrm{mg}(n=8)$ or with saline vehicle $(n=5)$. The survival days post-inoculation of the $263 \mathrm{~K}$-infected Tg mice expressing hamster PrP were significantly longer in the drug-treated group than the vehicle-treated mice when a single intraperitoneal injection was administered on the same day of intracerebral infection (170 (mean) \pm 38 (SD) vs $72 \pm 8$, days post-inoculation, $p<0.0005$ ) (Fig. 1A). As previously reported by Doh-ura and co-workers, the compounds used in various combinations of timings and routes all exhibited a protective role in the infected animals [8]. To provide the proof-of-evidence, we selected one of the combinations for the compound administration in our current study. Our result indicated that TC-5RW effectively slowed the progression of the disease.

To determine how TC-5RW treatment affected PrP deposition and neuropathological changes in the brain of infected animals, we compared the $\mathrm{PrP}^{\mathrm{Sc}}$ deposition and spongiform degeneration in the brain of animals treated with TC-5RW or saline vehicle using PET blotting and H\&E staining. Compared to vehicle-treated mice (Fig. 1B, right upper panels), the TC-5RW-treated mice exhibited substantially decreased $\mathrm{PrP}^{\mathrm{Sc}}$ staining in both the thalamus $(\mathrm{TH})$ and the hippocampus (HP) brain regions (Fig. 1B, left upper panels). Remarkably, the spongiform degeneration was considerably decreased in the brain of TC-5RW-treated than vehicle-treated mice (Fig. 1B, lower panels). In sum, the TC-5RW treatment greatly prolonged the survival time and decreased $\mathrm{PrP}^{\mathrm{Sc}}$ deposition and neuronal lesions in the brain of prion-infected mice.

\section{Prion-Seeding Activity Is Undetectable in the Skin Tissues of $263 \mathrm{~K}$-Infected Mice Treated with TC-5RW by RT-QuIC and sPMCA}

To determine whether the extended incubation periods associated with TC-5RW-treatment correlate with any changes
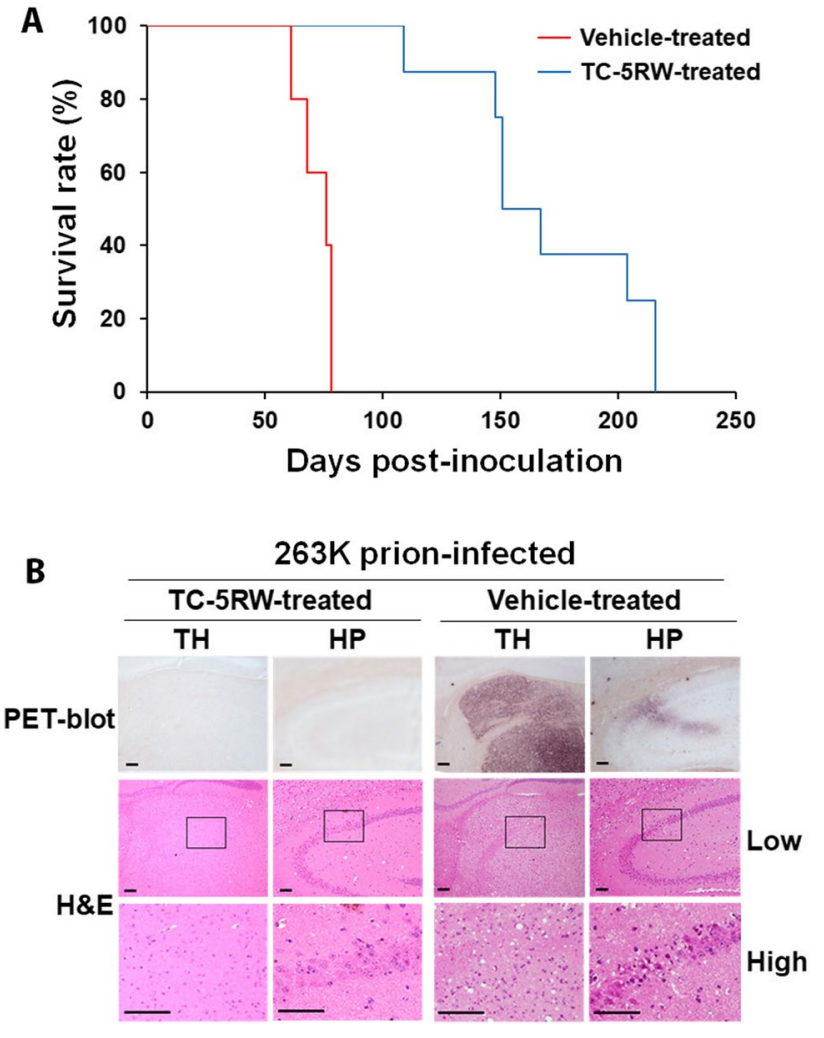

Fig. 1 Therapeutic effect of TC-5RW. A Survival rate of $263 \mathrm{~K}$-infected $\mathrm{Tg} 7$ mice given intraperitoneally either with a single TC-5WR dose (blue line) or with an equal volume of saline (vehicle controls, red line) on the same day for intracerebral inoculation with $263 \mathrm{~K}$ prion strain. B Histopathological examination of brain tissues of 263 K-infected Tg7 mice. Magnified PET-blot images and corresponding $\mathrm{H} \& \mathrm{E}$ staining images, obtained from the serial brain sections, are shown for the thalamus (TH) and hippocampus (HP) of the $263 \mathrm{~K}$-infected mouse intraperitoneally given TC-5RW (sample \#TC4) or saline (vehicle control; sample \#V4). The areas surrounded by squares in the low-magnification photos are enlarged in the highmagnification images. The bar scale indicates $50 \mu \mathrm{m}$. It was noted that histopathological changes such as vacuolation in the thalamus and neuronal cell loss in the CA2 of the hippocampus were parallel to $\operatorname{PrP}^{\mathrm{Sc}}$ deposition and much more remarkable in the vehicle control

in the levels of prion-seeding activity in the skin, next we performed highly sensitive RT-QuIC and SPMCA assays for detection of skin prion-seeding activity. The RT-QuIC result demonstrated that similar to the negative control (Neg CTL) all TC-5RW-treated mice (TC1-TC7) exhibited virtually no skin ThT reaction except for one (sample TC8) that showed a very weak ThT reaction after $55 \mathrm{~h}$; in contrast, skin samples of all prion-infected control mice treated with vehicle (V1V5) were found positive ThT reaction, similar to the infected positive control (Pos CTL) (Fig. 2A). Moreover, consistent with RT-QuIC assay, 2-4 rounds of sPMCA detected no $\mathrm{PrP}^{\mathrm{res}}$ in the skin tissues of the TC-5RW-treated mice (TC1TC8), but PrP ${ }^{\text {res }}$ was detected in the skin from the vehicletreated mice (V1-V5) (Fig. 2B-D). As controls, skin samples 
Fig. 2 Detection of skin prion-seeding activity in 263 K-infected $\mathrm{Tg}$ mice by RT-QuIC and sPMCA. A Blinded RT-QuIC assay of prion-seeding activity in skin samples from $263 \mathrm{~K}$-infected $\mathrm{Tg} 7$ mice treated with TC-5RW (TC1-8) or saline (vehicle-treated, V1-5). Pos CTL: positive controls with brain homogenate from a $263 \mathrm{~K}$-infected hamster as the seed; Neg CTL: negative controls with brain homogenate from a healthy hamster as the seed. Dotted line represents the threshold that defines the positive and negative seeding activity based on the average ThT fluorescence of negative controls plus three SD. B Western blotting of blinded sPMCA products of skin samples from 263 K-infected Tg7 mice injected with TC-5RW (TC1-8). Normal brain homogenate without PK treatment was used as a control (S1). C Western blotting of blinded sPMCA products of skin samples from $263 \mathrm{~K}$-infected $\mathrm{Tg} 7$ mice given saline (vehicle controls, V1-5) and non-infected $\mathrm{Tg} 7$ mouse controls (N1-3). D Western blotting of blinded sPMCA products of skin samples from non-infected $\mathrm{Tg} 7$ mouse (N4) as well as with normal control (Neg) and $263 \mathrm{~K}$-infected hamster control (Pos) brain homogenate as seeds and no seeds control (blank: Bl). In the sPMCA experiment, there were 2 sets of positive and negative controls. The infected $\mathrm{Tg}$ mice treated with saline (vehicle controls, V1-V5) served as positive controls while uninfected Tg mice (N1-N4) served as negative controls for our animal study. In addition, the $263 \mathrm{~K}$-infected hamster brain homogenates were used as positive controls while both uninfected hamster brain homogenates and SPMCA reaction without seeds (BI) served as negative controls of sPMCA to make sure that SPMCA worked. The sPMCA samples were 2-4 rounds of sPMCA products and were treated with PK prior to Western blotting probing with $3 \mathrm{~F} 4$

of infected $\mathrm{Tg}$ mice amplified $\mathrm{PrP}^{\text {res }}$ while skin samples from non-infected (N1-N4), negative control (Neg), and samples without seeds (Bl) showed no PrP ${ }^{\text {res }}$. Taken together, our RTQuIC and sPMCA results indicate that TC-5RW treatment reduced the deposition and formation of $\mathrm{PrP}^{\mathrm{Sc}}$ in the skin of infected $\mathrm{Tg}$ mice, reminiscent of its effect on brain $\operatorname{PrP}^{\mathrm{Sc}}$.

\section{TC-5RW Inhibits Skin Prion-Seeding Activity and PrP ${ }^{\text {Sc }}$ Amplification In Vitro}

Next, we determined whether the lack of detectable $\mathrm{PrP}^{\mathrm{Sc}}$-seeding activity in skin tissues of animals treated with TC-5RW is due to the inhibition of the $\operatorname{PrP}^{\mathrm{Sc}}$ amplification by residual TC-5RW left in the skin. Based on the previous observation, approximately less than $0.5-1 \mathrm{mg}$ of TC-5RW/ gram tissue was expected to be left in the skin sample [8]. To test this possibility, we added different amounts of TC-5RW ranging from 0 to $50 \mu \mathrm{g} / \mathrm{mL}$ into the $\mathrm{RT}$-QuIC in vitro assay of brain homogenates from $263 \mathrm{~K}$-infected animals. Dosedependent inhibitory effect of TC-5RW on ThT fluorescence intensity was observed (Fig. 3A).

We also examined the effect of TC-5RW on sPMCA of brain $\mathrm{PrP}^{\mathrm{Sc}}$ in vitro. We added different amounts of TC-5RW in the sPMCA substrates, with $263 \mathrm{~K}$-infected hamster brain homogenate as seeds, to verify the influence of TC-5RW on sPMCA of brain $\mathrm{PrP}^{\mathrm{Sc}}$. Compared to non-PMCA samples, amplification of $\mathrm{PrP}^{\mathrm{Sc}}$ was only observed in the samples without TC-5RW but not in samples with different amounts of TC-5RW (Fig. 3B).

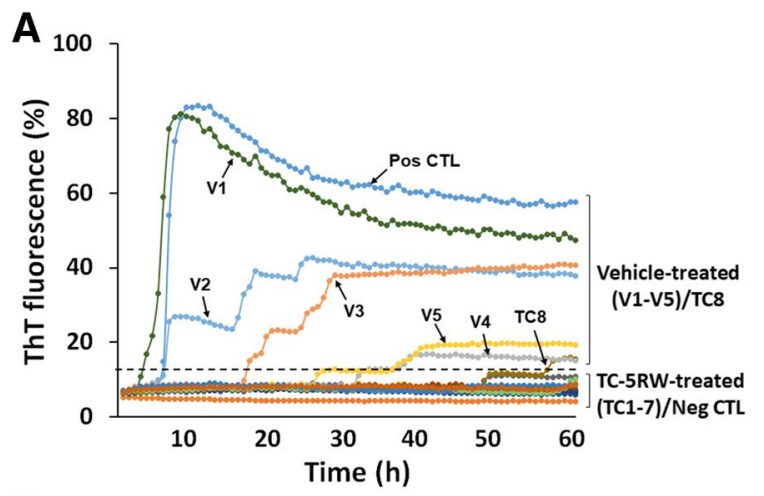

B
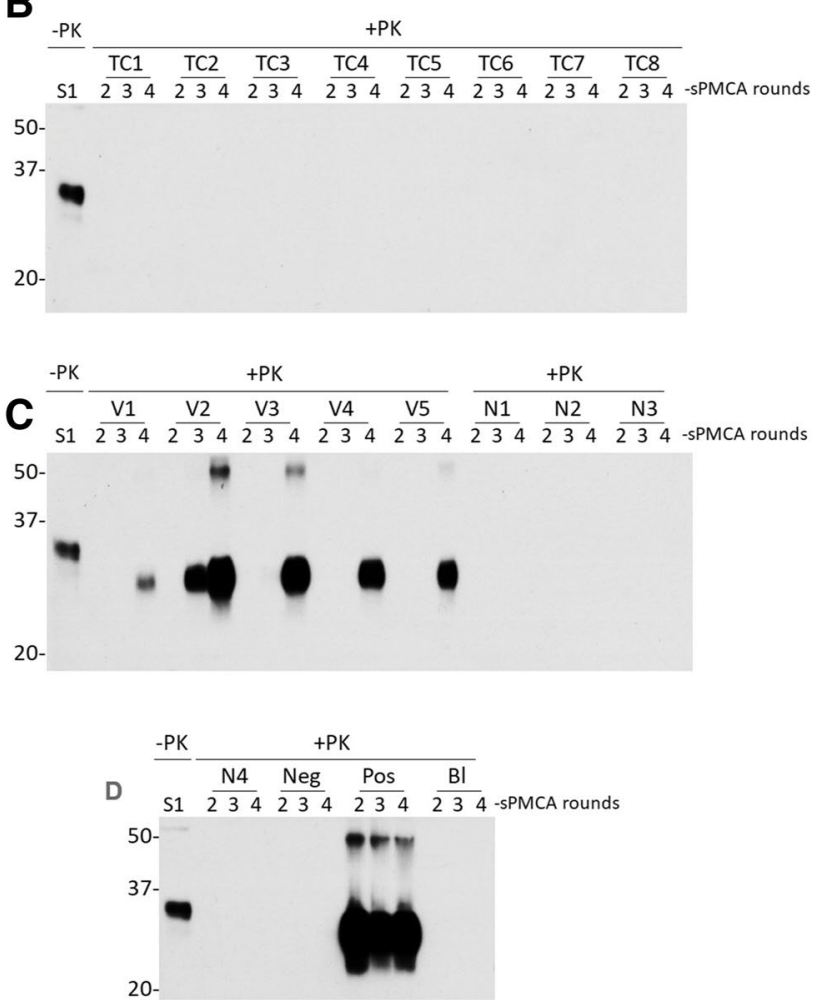

The same inhibitory effect of TC-5RW on prion-seeding activity was also detected by RT-QuIC assay in the skin samples. More than $50 \%$ ThT intensity of skin prion was inhibited in the presence of $2 \mu \mathrm{g} / \mathrm{mL}$ of TC-5RW while it was completely inhibited in the presence of $10 \mu \mathrm{g} / \mathrm{mL}$ or higher of TC-5RW (Fig. 3C). Moreover, the lag time of RTQuIC was significantly increased compared to the sample without the compound ( 38 vs $\sim 8$ h) (Fig. 3C).

\section{TC-5RW Treatment Does Not Affect 2D Profile of Brain PrP But Inhibits PrP ${ }^{\mathrm{Sc}}$ Amplification by sPMCA In Vitro}

Two-dimensional (2D) gel electrophoresis coupled with Western blotting is a high-resolution technique that is able to reflect not only molecular weights but also charges of 

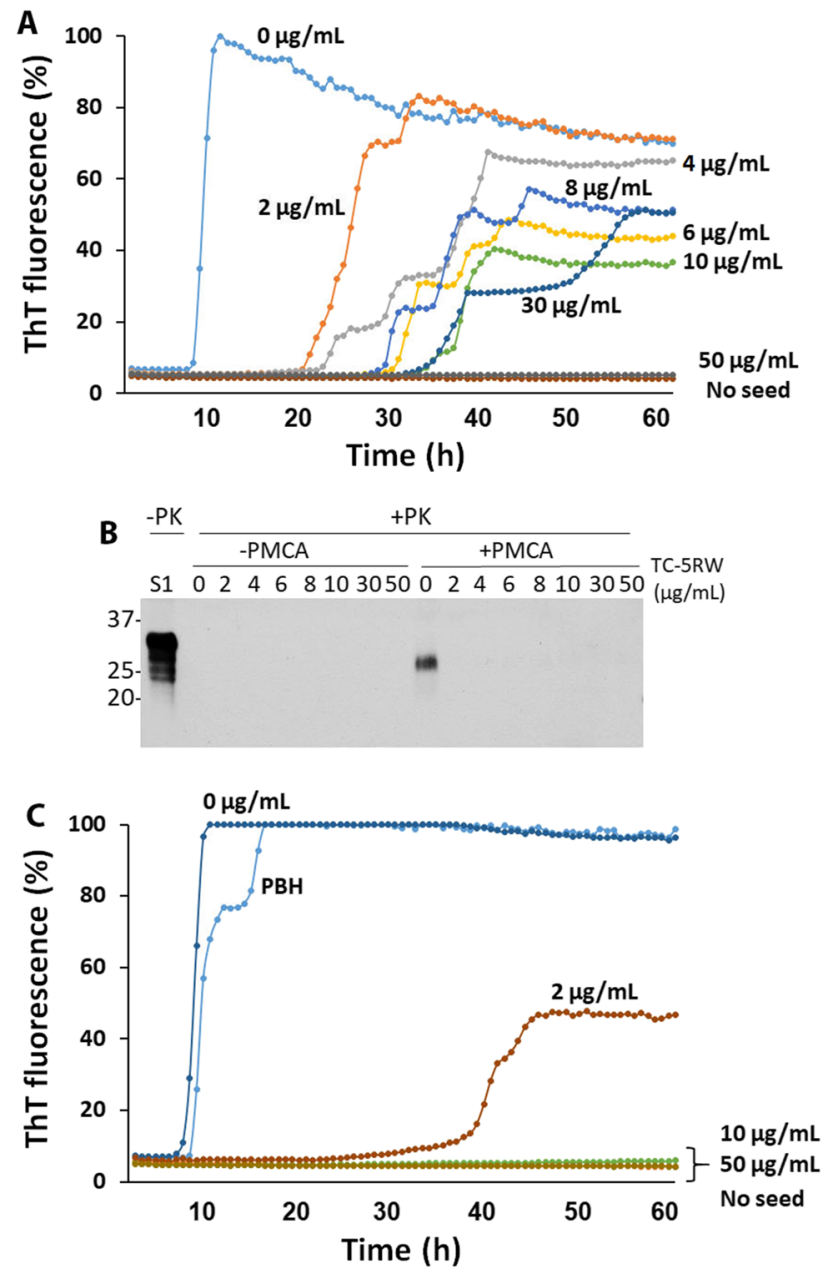

Fig. 3 Inhibition of $\mathrm{PrP}^{\mathrm{Sc}}$-seeding activity by $\mathrm{TC}-5 \mathrm{RW}$ in vitro. A RT-QuIC assay of prion-seeding activity of brain homogenates from $263 \mathrm{~K}$-infected hamsters in the presence of different amounts of TC5RW ranging from $0-50 \mu \mathrm{g} / \mathrm{mL}$. B Western blotting of PK-resistant $\mathrm{PrP}^{\mathrm{Sc}}$ of $263 \mathrm{~K}$-infected hamster sPMCA products (+ PMCA, right panel) and samples without sPMCA (-PMCA, left panel) in the presence of different amounts of TC-5RW $(0-50 \mu \mathrm{g} / \mathrm{mL})$. C RTQuIC assay of prion-seeding activity of skin homogenates from $263 \mathrm{~K}$-infected $\mathrm{Tg} 7$ mice expressing hamster $\mathrm{PrP}^{\mathrm{C}}$ in the presence of different amounts of TC-5RW ranging from $0-50 \mu \mathrm{g} / \mathrm{mL}$. PBH, positive brain homogenate. No seed in A and $\mathbf{C}$ RT-QuIC without brain homogenate seeds as a control to exclude spontaneous seeding activity

proteins interested, molecular characteristics that can be affected by therapeutic compounds. To determine whether TC-5RW treatment changes molecular weight and charges of PrP in the brain of prion-infected mice, we compared the 2D gel profile of PrP molecules from mice administered with TC-5RW or saline vehicle. 2D gel electrophoresis and Western blotting showed no differences in 2D gel profiles between the two groups (Fig. 4A), suggesting that the compound affects no post-translational modification. Most of the diglycosylated PrP spots were located on the basic side with
pI 6-10 and molecular weights at 33-35 kDa, while most of the mono-glycosylated PrP spots migrated in the acidic side pI 4-6.5 and molecular weights at 27-29 kDa (Fig. 4A).

Consistent with previous findings [8, 10], our RT-QuIC and SPMCA assays also revealed that TC-5RW inhibited seeding activity and amplification of $\mathrm{PrP}^{\mathrm{Sc}}$ from both brain and skin tissues in vitro (Figs. 2 and 3). However, it is unknown whether the compound has any direct effect on $\mathrm{PrP}^{\mathrm{Sc}}$. To address this issue, we incubated brain homogenates of $263 \mathrm{~K}$ prion-infected hamster with different amounts of TC-5RW at $37{ }^{\circ} \mathrm{C}$ for $2 \mathrm{~h}$. The levels of $\mathrm{PrP}^{\text {res }}$ were determined by western blotting after PK treatment of hamster $263 \mathrm{~K}$ brain homogenates that were subjected to incubation with different amounts of TC-5RW. We observed that the incubation of brain homogenates with TC-5RW at as low as $4 \mu \mathrm{g} / \mathrm{mL}$ decreased the intensity of $\operatorname{PrP}^{\text {res }}$ by approximately $80 \%$ when compared to untreated samples (Fig. 4B and 4C).

We also determined the effect of incubation time of TC-5RW with brain homogenates on the levels of $\mathrm{PrP}^{\mathrm{res}}$. After incubation for $1 \mathrm{~h}$, the levels of $\operatorname{PrP}^{\text {res }}$ were decreased approximately $60 \%$ when compared to that at the time zero (Fig. 4D and 4E). In sum, incubation of TC-5RW with $\mathrm{PrP}^{\mathrm{Sc}}$ can directly reduce the level of hamster PK-resistant $\mathrm{PrP}^{\mathrm{Sc}}$.

\section{TC-5RW Treatment Directly Decreases Human PK-Resistant PrPSC In Vitro}

To date, the inhibitory effect of CEs on $\mathrm{PrP}^{\mathrm{Sc}}$ conversion has been observed in rodent and other animal prions, but no studies with human prions have been reported. Next, we determined whether TC-5RW has an inhibitory effect on human $\mathrm{PrP}^{\mathrm{Sc}}$. Different amounts of TC-5RW from 0-50 $\mu \mathrm{g} /$ $\mathrm{mL}$ were added into the sPMCA reaction in which $\operatorname{PrP}^{\mathrm{Sc}}$ in brain homogenates from sCJDMM1 (MM1) or SCJDMM2 (MM2) were seeded in the normal brain homogenates of humanized $\mathrm{Tg}$ mice $(\mathrm{Tg} 40 \mathrm{~h})$ expressing human wild-type $\operatorname{PrP}^{\mathrm{C}}$ with 129-MM polymorphism [22]. The PK-resistant $\mathrm{PrP}^{\mathrm{res}}$ was detected in the both sCJDMM1 and sCJDMM2 sPMCA products without TC-5RW. In contrast, no PrP ${ }^{\text {res }}$ was detected in the sPMCA products of sCJDMM1 or sCJDMM2 in the presence of TC-5RW (Supplementary Fig. 1). Although $\mathrm{PrP}^{\mathrm{res}}$ was still detected in SCJDMM2 sPMCA product in the presence of $2 \mu \mathrm{g} / \mathrm{mL}$ of TC-5RW, its level was significantly decreased compared to that in the sample without TC-5RW.

To determine whether TC-5RW also has a direct effect on PK-resistant human $\operatorname{PrP}^{\mathrm{Sc}}$, the brain homogenates from sCJDMM1, sCJDMV2, sCJDVV2, fCJD $^{\mathrm{E} 200 \mathrm{~K}}$, FFI, and fCJD ${ }^{\text {V180I }}$ were incubated with different amounts of TC-5RW $(0-30 \mu \mathrm{g} / \mathrm{mL})$ at $37{ }^{\circ} \mathrm{C}$ for $2 \mathrm{~h}$. The level of PK-resistant $\operatorname{PrP}^{\mathrm{Sc}}$ was detected by Western blotting probed with the anti-PrP antibody 3F4 after PK treatment. Similar to hamster $263 \mathrm{~K}$ prion, in vitro TC-5RW 
Fig. 4 The effect of TC-5RW on hamster brain PrP in vivo and in vitro. A Two-dimensional (2D) analysis of brain PrP from $263 \mathrm{~K}$ prion-infected $\mathrm{Tg} 7$ mice injected with TC-5RW (TC-5RW treated) or saline (vehicle treated). B Representative Western blotting of PKresistant $\mathrm{PrP}^{\mathrm{Sc}}$ in the brain homogenates from $263 \mathrm{~K}$-infected hamsters after incubation with different amounts of TC-5RW ranging from $0-30 \mu \mathrm{g} / \mathrm{mL}$ at $37{ }^{\circ} \mathrm{C}$ for $2 \mathrm{~h}$. C Quantitative analysis of $\operatorname{PrP}^{\mathrm{Sc}}$ percentage of TC-5RW-treated/untreated brain homogenates based on Western blot analysis in B. D Representative Western blotting of PKresistant $\mathrm{PrP}^{\mathrm{Sc}}$ in the brain homogenates from $263 \mathrm{~K}$-infected hamsters after incubation with $10 \mu \mathrm{g} / \mathrm{mL}$ at $37^{\circ} \mathrm{C}$ at different time points ranging from $0-4 \mathrm{~h}$. E Quantitative analysis of $\mathrm{PrP}^{\mathrm{Sc}}$ percentage of TC-5RW-treated/untreated brain homogenates based on Western blot analysis in D. S1: the supernatant of brain homogenate after lowspeed centrifugation without PK treatment as a control

incubation significantly decreased the levels of PK-resistant $\mathrm{PrP}^{\mathrm{Sc}}$ from various human prion diseases including most common subtypes of SCJD and FCJD at concentrations as low as $2 \mu \mathrm{g} / \mathrm{mL}$, except for FFI that started to show a significant decrease at $6 \mu \mathrm{g} / \mathrm{mL}$ (Fig. 5). In addition, we also examined the effect of TC-5RW on human $\mathrm{PrP}^{\text {res }}$ at $-20^{\circ} \mathrm{C}$. Interestingly, after incubation of brain homogenates from sCJDVV2 with different amounts of TC-5RW from $0,2,4,6,8,10$, and $30 \mu \mathrm{g} / \mathrm{mL}$, the levels of $\mathrm{PrP}^{\mathrm{res}}$ were also dramatically decreased (Supplementary Fig. 2).

\section{TC-5RW Inhibits Seeding Activity of Prions from Various Human Prion Diseases In Vitro}

We further investigated the effect of TC-5RW on the seeding activity of $\mathrm{PrP}^{\mathrm{Sc}}$ from various human prion diseases including sCJDMM1, sCJDMM2, sCJDMV2, sCJDVV2, fCJD $^{\mathrm{E} 200 \mathrm{~K}}$, FFI, and fCJD ${ }^{\mathrm{V} 180 \mathrm{I}}$ by RT-QuIC assay (Fig. 6A through G). Although TC-5RW exhibited an inhibitory effect on prion-seeding activity in all human prion diseases, FFI and CJDD $^{\text {V180I }}$ had better inhibitory effects compared to various subtypes of SCJD and $\mathrm{CCJD}^{\mathrm{E} 200 \mathrm{~K}}$ in terms of the lag times (Supplementary Table 1) (Fig. 6H) and maximal intensity of ThT fluorescence at the endpoint of reaction (Supplementary Table 2) (Fig. 6I). Taken together, as done with hamster $263 \mathrm{~K}$-prion, TC-5RW is also able to inhibit prion-seeding activity in various sporadic and genetic CJDs in vitro.

\section{TC-5RW Inhibits Seeding Activity of Prions from CWD Deer In Vitro}

Consistent with the previous study reported by Hannaoui et al. [10], we also found that TC-5RW was able to inhibit the seeding activity of $\operatorname{PrP}^{\mathrm{Sc}}$ from CWD deer in the RTQuIC assay. The compound significantly prolonged the lag time of ThT reaction upon an increase in the concentrations of TC-5RW (Supplementary Fig. 3). The ThT fluorescence

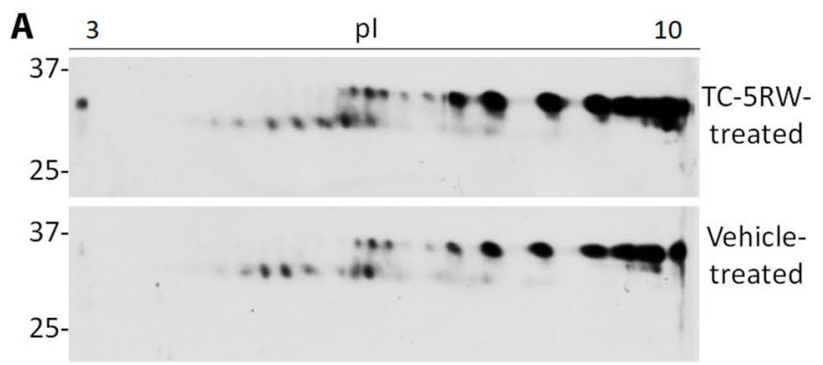

B
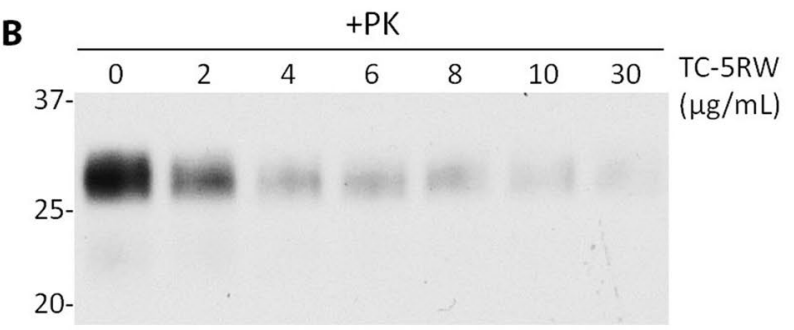

C
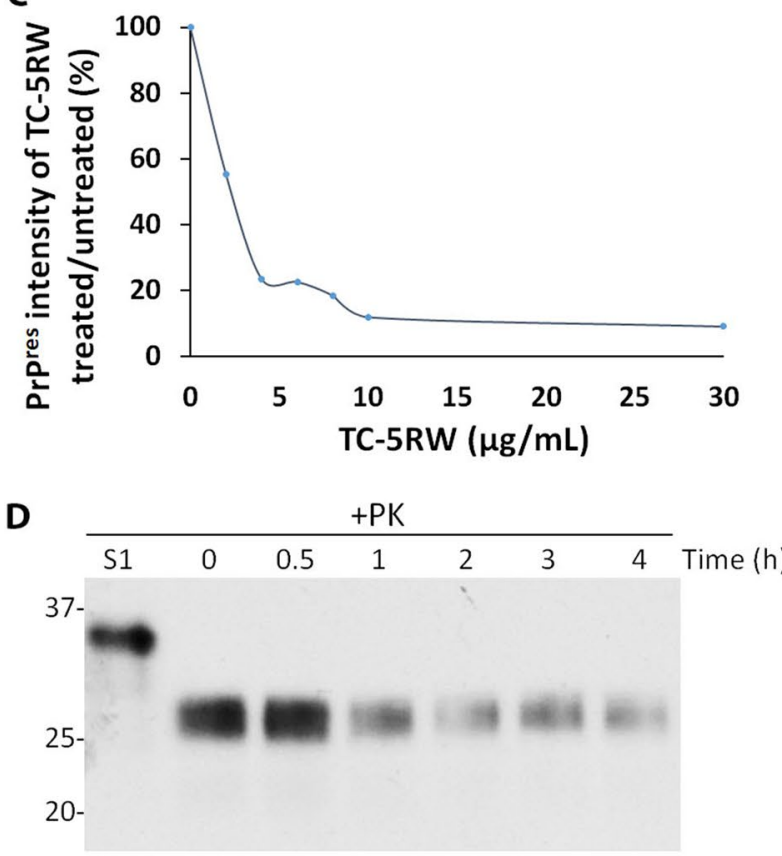

E

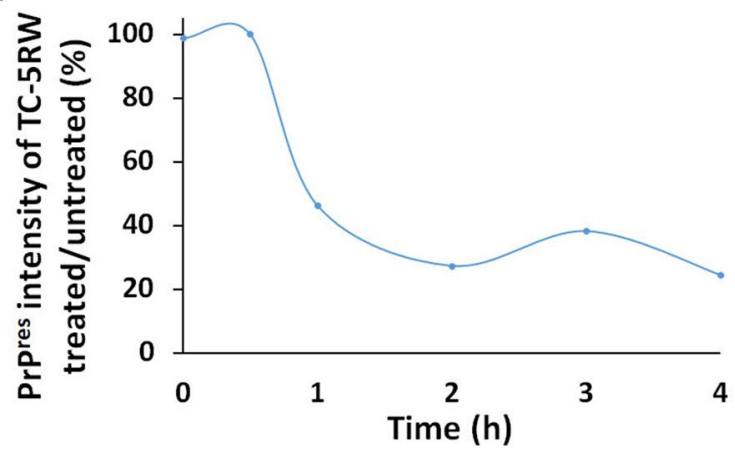

intensity was significantly decreased at $30 \mu \mathrm{g} / \mathrm{mL}$ while no ThT reaction was detected at $50 \mu \mathrm{g} / \mathrm{mL}$ of TC-5RW (Supplementary Fig. 3). 
Fig. 5 The effect of TC-5RW on human PK-resistant $\mathrm{PrP}^{\mathrm{Sc}}$ by in vitro incubation. Representative Western blotting of human $\mathrm{PK}$-resistant $\mathrm{PrP}^{\mathrm{Sc}}$ in the brain homogenates from SCJDMM1 (MM1, A), sCJDMV2 (MV2, B), sCJDVV2 (VV2, C), fCJD $^{\mathrm{E} 200 \mathrm{~K}}$ (E200K, D), FFI $(\mathbf{E})$, and $\mathrm{fCJD}^{\mathrm{V} 180 \mathrm{I}}(\mathrm{V} 180, \mathbf{F})$ after incubation with different amounts of TC-5RW ranging from $0-30 \mu \mathrm{g} / \mathrm{mL}$ at $37^{\circ} \mathrm{C}$ for 2 h. G Quantitative analysis of $\mathrm{PrP}^{\mathrm{Sc}}$ percentage of TC-5RW treated/untreated based on Western blot analyses in $\mathbf{A}$ through $\mathbf{F}$ above
A
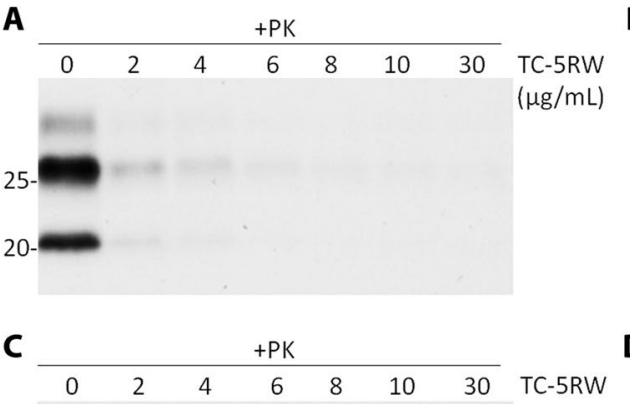

$\mathrm{TC}-5 \mathrm{RW}$
$(\mu \mathrm{g} / \mathrm{mL})$
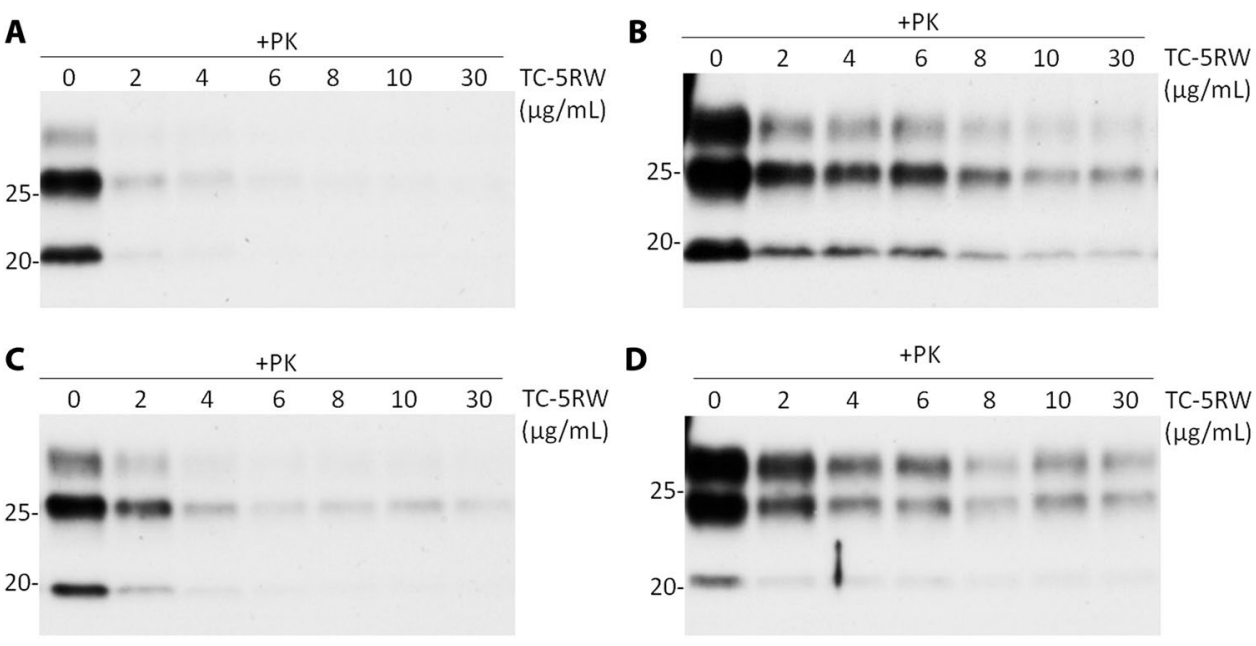

D $\quad+$ PK
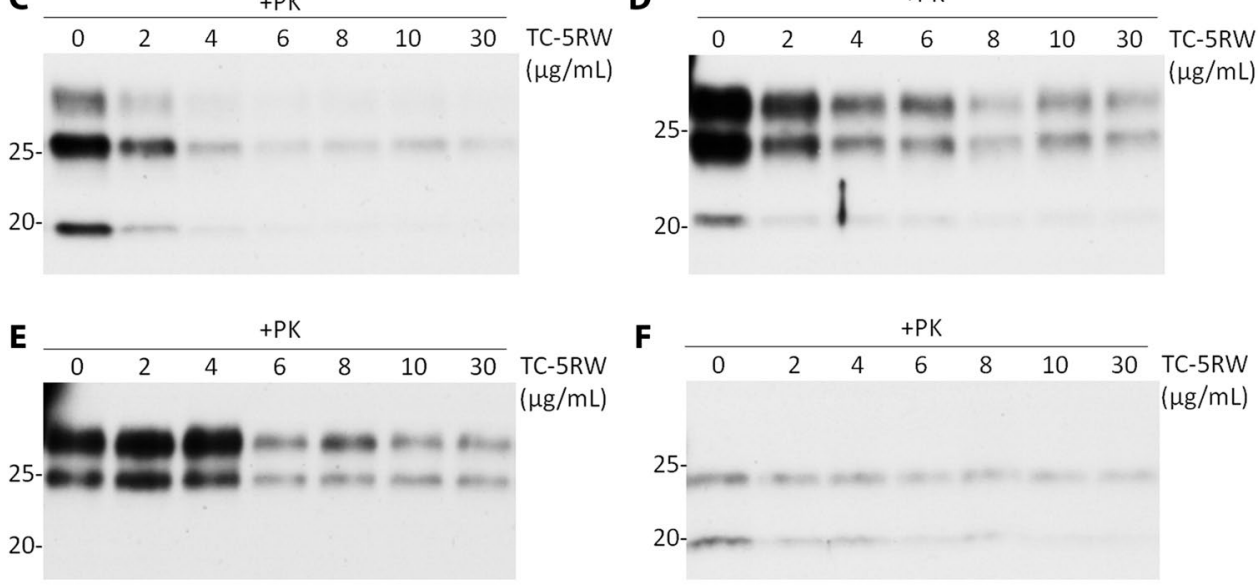

$\mathbf{F}$

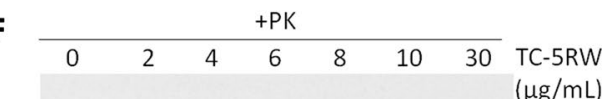

25

$20-2$

G

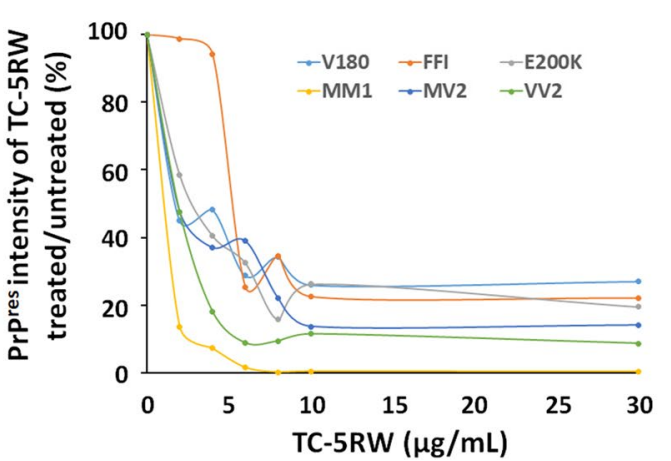

\section{Discussion}

In addition to confirming the therapeutic effect of TC-5RW, a CE compound, on $263 \mathrm{~K}$ prion-infected animals, our current study made several important new findings. First, seeding activity and amplification of skin $\mathrm{PrP}^{\mathrm{Sc}}$ were significantly inhibited in $263 \mathrm{~K}$-infected animals treated with TC-5RW, reflecting the reduced levels of $\mathrm{PrP}^{\mathrm{Sc}}$ in the brain after TC-5RW treatment. This may indicate prion seeding in the skin as a potential biomarker for monitoring the therapeutic efficacy of compounds. Second, TC-5RW exhibited an inhibitory effect on the seeding activity of $\mathrm{PrP}^{\mathrm{Sc}}$ from various human prion diseases including sporadic and genetic CJD as well as FFI, suggesting that it may have therapeutic potential for human prion diseases. We also confirmed its inhibitory effect on CWD prions. Finally, incubation of $\operatorname{PrP}^{\mathrm{Sc}}$ with TC-5RW directly decreased the level of PK-resistant $\mathrm{PrP}^{\mathrm{Sc}}$, a function similar to detergents such as guanidine hydrochloride that may dissociate $\mathrm{PrP}^{\mathrm{Sc}}$ aggregates, suggesting that it may be used for decontamination of prions.

There are no cures for the fatal transmissible prion diseases including CJD in humans. The lack of an operational assay to assess the therapeutic efficacy in clinical trials of prion diseases limits screening effective compounds for the treatment. The pathogenesis and disease progression of prion disease are highly associated with the accumulation of $\mathrm{PrP}^{\mathrm{Sc}}$ in the brain. The current detection of $\mathrm{PrP}^{\mathrm{Sc}}$ mainly depends on examination of the brain tissues or maybe the cerebrospinal fluid (CSF) for prion-seeding activity by RTQuIC assay. However, due to the high risks of complications by these highly invasive procedures, it may not be practical to use brain biopsy or lumbar puncture for routine followup in clinical trials. Remarkably, our recent study indicated that $\mathrm{PrP}^{\mathrm{Sc}}$ can be detected in the skin tissues of CJD patients [3] and could be a biomarker for early preclinical diagnosis of prion disease [5]. Our present study indicated that 

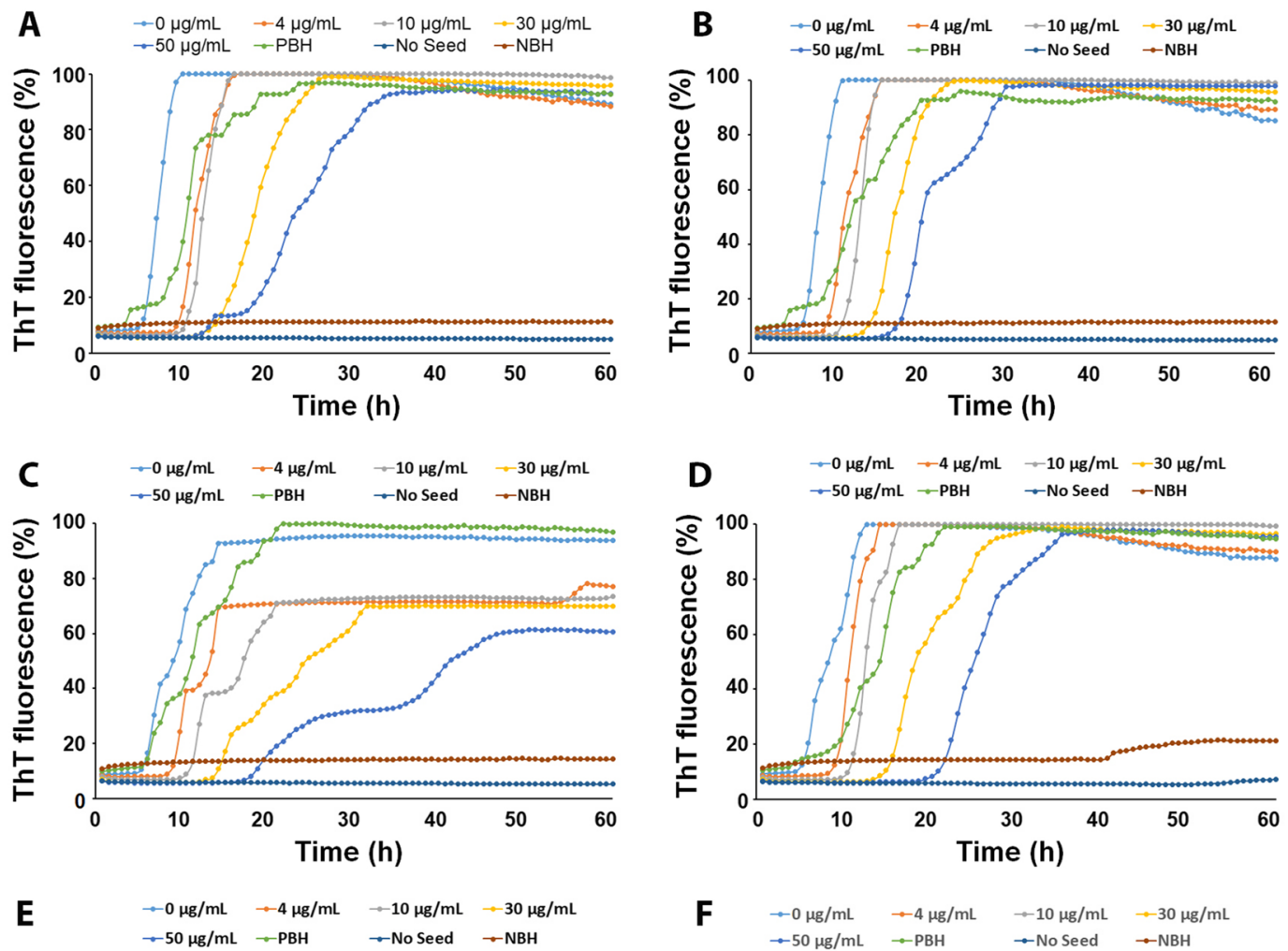

$$
\text { F } \rightarrow 0 \mu \mathrm{g} / \mathrm{mL} \quad \rightarrow-4 \mu \mathrm{g} / \mathrm{mL} \quad \rightarrow-10 \mu \mathrm{g} / \mathrm{mL} \quad \rightarrow-30 \mu \mathrm{g} / \mathrm{mL}
$$
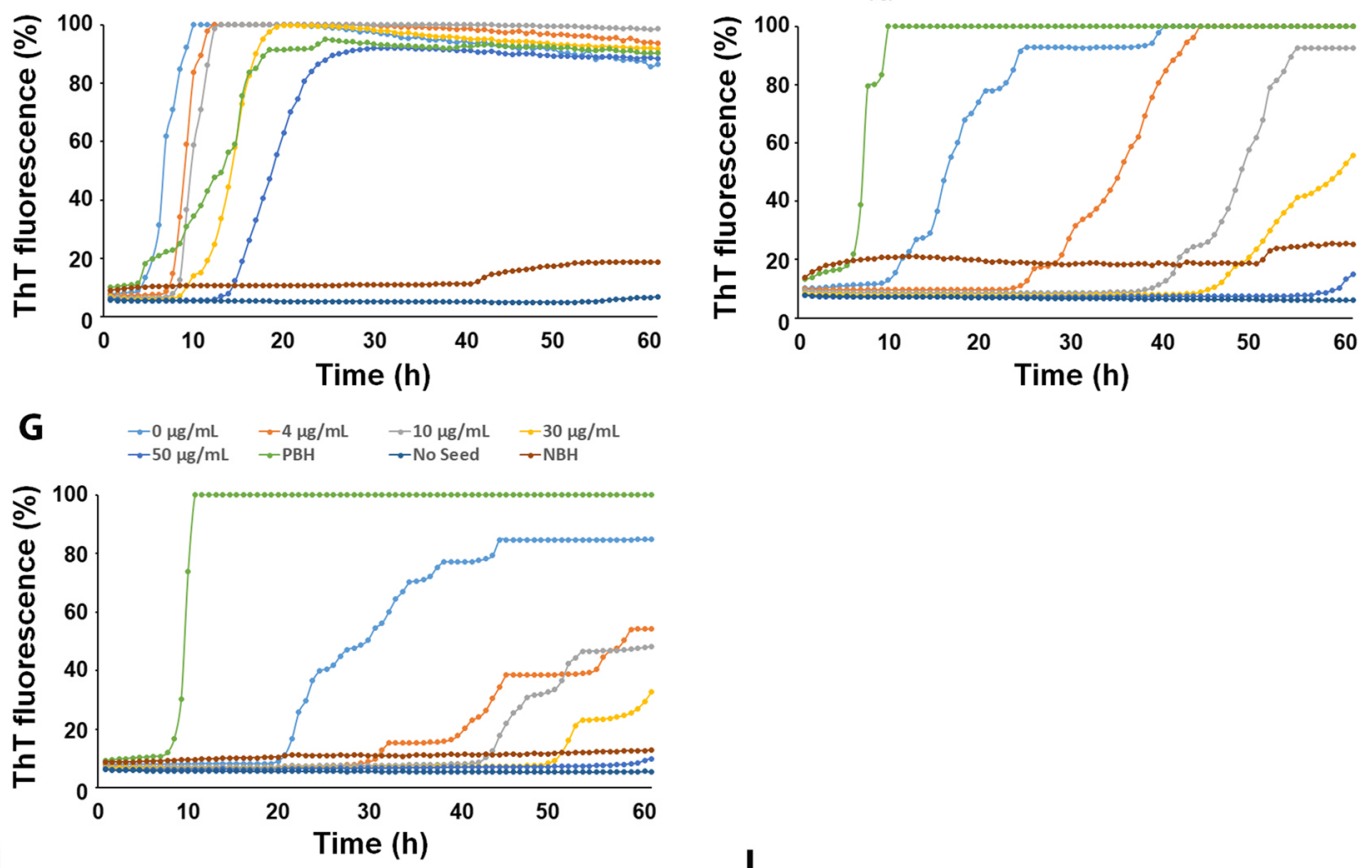

H

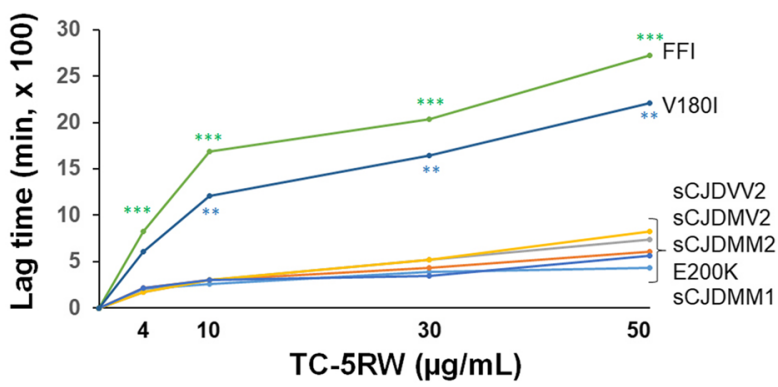

I

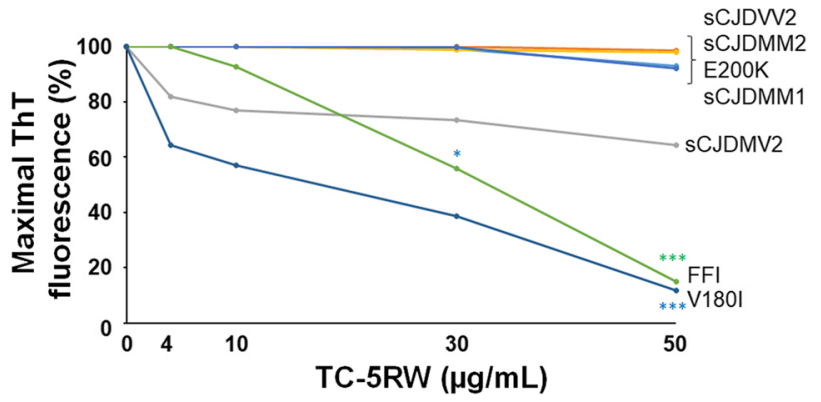


4Fig. 6 The effect of TC-5RW on seeding activity of $\operatorname{PrP}^{\mathrm{Sc}}$ from various human prion diseases. RT-QuIC spectra of seeding activity of $\mathrm{PrP}^{\mathrm{Sc}}$ in the brain homogenates from sCJDMM1 (A), sCJDMM2 (B), sCJDMV2 (C), sCJDVV2 (D), fCJD ${ }^{\mathrm{E} 200 \mathrm{~K}}(\mathbf{E})$, FFI (F), and $\mathrm{fCJD}^{\mathrm{V} 180 \mathrm{I}}(\mathbf{G})$ in the presence of different amounts of TC-5RW ranging from $0-50 \mu \mathrm{g} / \mathrm{mL}$. H Comparison of the lag time of seeding activity of $\operatorname{PrP}^{\mathrm{Sc}}$ from sCJDMM1, sCJDMM2, sCJDMV2, sCJDVV2, $\mathrm{fCJD}^{\mathrm{E} 200 \mathrm{~K}}$, FFI, and $\mathrm{fCJD}^{\mathrm{V} 180 \mathrm{I}}$. Green $* * * p<0.001$ for comparing lag time between FFI and sCJDMM1 at different TC-5RW concentrations. Blue $* * p<0.01$ for comparing the lag time between V180I and SCJDMM1 at different TC-5RW concentrations. I Comparison of ThT intensity at the endpoint of RT-QuIC reaction of $\operatorname{PrP}^{\mathrm{Sc}}$ from sCJDMM1, sCJDMM2, sCJDMV2, sCJDVV2, fCJD ${ }^{\mathrm{E} 200 \mathrm{~K}}$, FFI, and $\mathrm{fCJD}^{\mathrm{V} 180 \mathrm{I}}$. Green $*$ and $* * * p<0.05$ or $<0.001$ for comparing ThT fluorescence intensity between FFI and SCJDMM1 at TC-5RW concentration of $30 \mu \mathrm{g} / \mathrm{mL}$ or $50 \mu \mathrm{g} / \mathrm{mL}$, respectively. Blue $* * * p<0.001$ for comparing ThT fluorescence intensity between V180I and sCJDMM1 at TC-5RW concentration of $50 \mu \mathrm{g} / \mathrm{mL}$

seeding activity and amplification capability of skin $\mathrm{PrP}^{\mathrm{Sc}}$ were undetectable when the $\operatorname{Tg} 7$ mice were given therapeutic compound TC-5RW and showed prolonged lifespan compared to vehicle-treated mice. This finding provided a proof-of-concept evidence that skin prion-seeding activity may serve as a biomarker for monitoring therapeutic efficacy in clinical trials of prion diseases. Biomarkers have been believed as critical to the discovery and development of disease therapeutics. For instance, skin prion-seeding activity could provide an early indication of therapeutic target brain prion improvement, thereby adjusting clinical trial design and allowing successful therapeutic development. Moreover, skin prion-seeding activity may also allow evaluating therapeutic intervention on disease progression. A skin punch biopsy is a less invasive procedure than a spinal tap; it can be conducted for outpatients. Therefore, detection of prions in the skin would be a highly valuable biomarker for evaluation of therapeutic efficacy in clinical trials, in addition to the diagnosis of prion diseases. This can be tested in human prion-infected humanized mice in the future.

Cellulose ethers (CEs) have already widely been used as inactive ingredients in foods and pharmaceuticals. It has been observed that CEs do not modify prion protein expression but inhibit $\mathrm{PrP}^{\mathrm{Sc}}$ formation in vitro and in prioninfected cells $[8,10]$. Importantly, they have pre- or postinfection prophylactic effects and post-symptomatic therapeutic effects in prion-infected rodents [8]. Our current study observed that the CE compound TC-5RW is able to not only inhibit the seeding activity of $\mathrm{PrP}^{\mathrm{Sc}}$ but also directly decrease $\mathrm{PK}$-resistant $\mathrm{PrP}^{\mathrm{Sc}}$ in various human prion diseases including the most common form of SCJD (sCJDMM1) and genetic CJD. Therefore, it is most likely that CEs can be used for clinical trials of human prion diseases. Especially, it will be of high clinical value for asymptomatic PrP mutation carriers since CEs have been proved to have pre-infection prophylactic effects in animals in the previous study [8]. Interestingly, we observed that TC-5RW showed a better inhibitory effect for two genetic prion diseases compared to other sCJD subtypes. However, this finding has not been validated in humans yet. Therefore, it will be interesting to determine whether CEs have a prophylactic effect in asymptomatic carriers of PrP mutations that are associated with various familial prion diseases. It has been known that most of these asymptomatic PrP mutation carriers will inevitably develop familial prion diseases during aging. It is possible that the incapability of RT-QuIC to detect skin prion-seeding activity in TC-5RW-treated Tg mice may partially result from the inhibitive effect of TC-5RW on seeding activity of RT-QuIC assay in vitro. However, our RT-QuIC assay revealed that the skin prion-seeding activity of RT-QuIC could not be completely inhibited until $50 \mu \mathrm{g} / \mathrm{mL}$ (Fig. 3A).

The exact mechanisms underlying extending survival time of infected animals by CEs remain unclear. Indeed, the levels of PK-resistant $\mathrm{PrP}^{\mathrm{Sc}}$ have been found to decrease compared to the infected animals without CE treatment [10], consistent with our current finding with PET blotting of brain tissue sections from infected animals. Moreover, TC-5RW has been observed to inhibit the prion amplification capability of sPMCA and seeding activity of $\mathrm{PrP}^{\mathrm{Sc}}$ seeds through RTQuIC in vitro by previous studies $[8,10]$ and our current study. In addition, the inhibitory effect of CEs on $\mathrm{PrP}^{\mathrm{Sc}}$ formation also was found in a cell-based model of prion disease $[8,11]$. However, the CE concentration required for the inhibitory effect was believed to be dependent on the approach used [8]. For instance, the CE concentration of less than $10 \mu \mathrm{g} / \mathrm{g}$ tissue equivalent was needed for inhibition of hamster $\operatorname{PrP}^{\mathrm{Sc}}$ in vivo and in vitro while it required $\sim 1 \mathrm{mg} /$ $\mathrm{mL}$ in the cell model [8]. Indeed, the decreased levels of PKresistant $\mathrm{PrP}^{\mathrm{Sc}}$ in the brain of CWD-infected $\mathrm{Tg}$ mice were proposed to result from the alteration in the $\mathrm{PK}$ resistance of $\mathrm{PrP}^{\mathrm{Sc}}$ in the CE-treated mice [10]. However, it cannot be ruled out that the decrease in the levels of PK-resistant $\mathrm{PrP}^{\mathrm{Sc}}$ in the brain of the CEs-treated mice could just result from the inhibitory effect of CEs on the conversion of $\operatorname{PrP}^{\mathrm{C}}$ into $\mathrm{PrP}^{\mathrm{Sc}}$ or $\mathrm{PrP}^{\mathrm{Sc}}$ formation in vivo. This is because that the levels of PK-resistant $\mathrm{PrP}^{\mathrm{Sc}}$ will be decreased if the $\mathrm{PrP}^{\mathrm{Sc}}$ formation is inhibited in the brain of $\mathrm{Tg}$ mice treated by CE compounds. Our new finding that TC-5RW is able to directly decrease the PK-resistant $\mathrm{PrP}^{\mathrm{Sc}}$ by direct incubation of brain homogenates with TC-5RW may represent another mechanism involved in its therapeutic effect. However, our study by in vitro directly incubating TC-5RW with brain homogenates from $263 \mathrm{~K}$-infected hamsters, CWD prioninfected deer, and various human prions-infected humans provided direct evidence that TC-5RW indeed alters PK resistance of $\mathrm{PrP}^{\mathrm{Sc}}$ either at $37{ }^{\circ} \mathrm{C}$ or even at $-20{ }^{\circ} \mathrm{C}$. The decrease in the levels of $\mathrm{PK}$-resistant $\mathrm{PrP}^{\mathrm{Sc}}$ by the direct incubation of RT-5RW with brain homogenates is reminiscent of a phenomenon that has been well demonstrated with guanidine hydrochloride [25-27]. It is possible that as 
guanidine hydrochloride, TC-5RW is also able to dissociate $\mathrm{PrP}^{\mathrm{Sc}}$ aggregates or change the conformation of $\mathrm{PrP}^{\mathrm{Sc}}$. It has been shown that CEs induced the conformation transition of silk fibroin from random coil form to $\beta$-sheet structure [28]. In contrast, in the case of the effect of CEs on $\mathrm{PrP}^{\mathrm{Sc}}$ conformation, whether TC-5RW may induce conversion of $\beta$-sheet structure into $\alpha$-helix structure remains to be determined.

Notably, the TC-5RW-treated mice with longer survival time had very milder cerebral lesions in the hippocampus and thalamus compared to the vehicle-treated mice. However, they were clinically in the terminal stage of the disease and died of prion disease ultimately. This apparent discrepancy may result from a possibility that TC-5RW may inhibit disease progression less effectively in the brainstem than in the cerebrum. This possibility will be clarified in the future. The other possibility is that TC-5RW may just reduce PKresistant $\mathrm{PrP}^{\mathrm{Sc}}$ but not PK-sensitive $\mathrm{PrP}^{\mathrm{Sc}}$, which may be echoed by the newly identified variably protease-sensitive prionopathy. The latter is characterized by the deposition in the brain of less PK-resistant $\operatorname{PrP}^{\mathrm{Sc}}$ but more PK-sensitive $\mathrm{PrP}^{\mathrm{Sc}}$ and exhibits a less severe brain damage and longer disease duration compared to SCJD [29-31].

Abbreviations $\operatorname{PrP}^{\mathrm{C}}$ : Cellular prion protein; $\mathrm{PrP}^{\mathrm{Sc}}$ : Scrapie isoform of prion protein; sCJD: Sporadic Creutzfeldt-Jakob disease; RTQuIC: Real-time quaking-induced conversion; PMCA: Protein misfolding cyclic amplification; Tg: Transgenic; 2D: Two-dimensional electrophoresis

Supplementary Information The online version contains supplementary material available at https://doi.org/10.1007/s12035-021-02418-6.

Acknowledgements We thank all donors for brain tissues and the families affected by CJD as well as physicians for support. We also want to thank Dr. Zerui Wang for technical help at the early stage of this study and the National Prion Disease Pathology Surveillance Center, Case Western Reserve University, for providing the brain tissues from sCJD patients and normal controls.

Author Contributions W.Q.Z. conceived the study. M.D., K.D., L.C., and W.Q.Z. designed the study. M.D., K.T., H.W.L., W.Z., J.Y., A.O., A.F., M.V.C., M.M. K.D., L.C., and W.Q.Z. performed experiments and interpreted data analyses. M.V.C. and Q.K. provided brain tissues of humanized $\mathrm{Tg} 40 \mathrm{~h}$ mice. J.J.G. provided CWD brain tissues. M.D., K.D., L.C., and W.Q.Z. wrote the first version of the paper. All authors critically reviewed, revised, and approved the final version of the manuscript.

Funding This research was funded in part by CJD Foundation and ALZ/ARUK/MJFF/Weston to W.Q.Z, the National Institutes of Health R01NS109532 to W.Q.Z. and Q.K, the National Natural Science Foundation of China (NNSFC) (No. 81671186) to L.C, and in part by the Japan Society for the Promotion of Science to K.T. (19K22479) and K.D. (19H03570), and the Japan Agency for Medical Research and Development to K.D. (16ek0109012h0003).

Data Availability All materials used in this study will be made available subject to a material transfer agreement.

\section{Declarations}

The use of autopsy human brain tissues was authorized by the Institutional Review Board of University Hospital Cleveland Medical Center and Case Western Reserve University, Cleveland, Ohio. The consents were received for each case through the National Prion Disease Pathology Surveillance Center (NPDPSC), Case Western Reserve University, Cleveland, Ohio, for research on retained tissues after written informed consents given by the patients during life or their next of kin after death. Postmortem examinations, if permission was available, were carried out in NPDPSC. All information was analyzed anonymously.

Consent for Publication The manuscript does not contain any individual person's data in any form.

Competing Interests The authors declare no competing interests.

Open Access This article is licensed under a Creative Commons Attribution 4.0 International License, which permits use, sharing, adaptation, distribution and reproduction in any medium or format, as long as you give appropriate credit to the original author(s) and the source, provide a link to the Creative Commons licence, and indicate if changes were made. The images or other third party material in this article are included in the article's Creative Commons licence, unless indicated otherwise in a credit line to the material. If material is not included in the article's Creative Commons licence and your intended use is not permitted by statutory regulation or exceeds the permitted use, you will need to obtain permission directly from the copyright holder. To view a copy of this licence, visit http://creativecommons.org/licenses/by/4.0/.

\section{References}

1. Das AS, Zou WQ (2016) Prions: beyond a single protein. Clin Microbiol Rev 29(3):633-658. https://doi.org/10.1128/CMR. 00046-15

2. Prusiner SB (1998) Prions. Proc Natl Acad Sci USA 95(23):13363-13383. https://doi.org/10.1073/pnas.95.23.13363

3. Orru CD, Yuan J, Appleby BS, Li B, Li Y, Winner D, Wang Z, Zhan YA et al (2017) Prion seeding activity and infectivity in skin samples from patients with sporadic Creutzfeldt-Jakob disease. Sci Transl Med. 9(417). https://doi.org/10.1126/scitranslmed. aam7785

4. Mammana A, Baiardi S, Rossi M, Franceschini A, Donadio V, Capellari S, Caughey B, Parchi P (2020) Detection of prions in skin punch biopsies of Creutzfeldt-Jakob disease patients. Ann Clin Transl Neurol 7(4):559-564. https://doi.org/10.1002/acn3. 51000

5. Wang Z, Manca M, Foutz A, Camacho MV, Raymond GJ, Race B, Orru CD, Yuan J et al (2019) Early preclinical detection of prions in the skin of prion-infected animals. Nat Commun 10(1):247. https://doi.org/10.1038/s41467-018-08130-9

6. Arca HC, Mosquera-Giraldo LI, Bi V, Xu D, Taylor LS, Edgar KJ (2018) Pharmaceutical applications of cellulose ethers and cellulose ether esters. Biomacromol 19(7):2351-2376. https://doi. org/10.1021/acs.biomac.8b00517

7. Alshehri SM, Aldalbahi A, Al-Hajji AB, Chaudhary AA, Panhuis MI, Alhokbany N, Ahamad T (2016) Development of carboxymethyl cellulose-based hydrogel and nanosilver composite as antimicrobial agents for UTI pathogens. Carbohydr Polym 138:229-236. https://doi.org/10.1016/j.carbpol.2015.11.004

8. Teruya K, Oguma A, Nishizawa K, Kawata M, Sakasegawa Y, Kamitakahara H, Doh-Ura K (2016) A single subcutaneous injection of cellulose ethers administered long before infection confers 
sustained protection against prion diseases in rodents. PLoS Pathog 12(12):e1006045. https://doi.org/10.1371/journal.ppat.10060 45

9. Abdulrahman BA, Tahir W, Doh-Ura K, Gilch S, Schatzl HM (2019) Combining autophagy stimulators and cellulose ethers for therapy against prion disease. Prion 13(1):185-196. https://doi. org/10.1080/19336896.2019.1670928

10. Hannaoui S, Arifin MI, Chang SC, Yu J, Gopalakrishnan P, DohUra K, Schatzl HM, Gilch S (2020) Cellulose ether treatment in vivo generates chronic wasting disease prions with reduced protease resistance and delayed disease progression. J Neurochem 152(6):727-740. https://doi.org/10.1111/jnc.14877

11. Nishizawa K, Teruya K, Oguma A, Sakasegawa Y, Schatzl H, Gilch S, Doh-Ura K (2019) Preparation and characterization of cellulose ether liposomes for the inhibition of prion formation in prion-infected cells. J Pharm Sci 108(8):2814-2820. https://doi. org/10.1016/j.xphs.2019.03.025

12. Kascsak RJ, Rubenstein R, Merz PA, Tonna-DeMasi M, Fersko R, Carp RI, Wisniewski HM, Diringer H (1987) Mouse polyclonal and monoclonal antibody to scrapie-associated fibril proteins. J Virol 61(12):3688-3693. https://doi.org/10.1128/JVI.61.12.36883693.1987

13. Zou WQ, Langeveld J, Xiao X, Chen S, McGeer PL, Yuan J, Payne MC, Kang HE et al (2010) PrP conformational transitions alter species preference of a PrP-specific antibody. J Biol Chem 285(18):13874-13884. https://doi.org/10.1074/jbc.M109.088831

14. Yuan J, Xiao X, McGeehan J, Dong Z, Cali I, Fujioka H, Kong Q, Kneale $\mathrm{G}$ et al (2006) Insoluble aggregates and protease-resistant conformers of prion protein in uninfected human brains. J Biol Chem 281(46):34848-34858. https://doi.org/10.1074/jbc.M6022 38200

15. Race RE, Priola SA, Bessen RA, Ernst D, Dockter J, Rall GF, Mucke L, Chesebro B et al (1995) Neuron-specific expression of a hamster prion protein minigene in transgenic mice induces susceptibility to hamster scrapie agent. Neuron 15(5):1183-1191. https://doi.org/10.1016/0896-6273(95)90105-1

16. Bueler H, Fischer M, Lang Y, Bluethmann H, Lipp HP, DeArmond SJ, Prusiner SB, Aguet M et al (1992) Normal development and behaviour of mice lacking the neuronal cell-surface PrP protein. Nature 356(6370):577-582. https://doi.org/10.1038/35657 $7 \mathrm{a} 0$

17. Kawasaki Y, Kawagoe K, Chen CJ, Teruya K, Sakasegawa Y, Doh-ura K (2007) Orally administered amyloidophilic compound is effective in prolonging the incubation periods of animals cerebrally infected with prion diseases in a prion strain-dependent manner. J Virol 81(23):12889-12898. https://doi.org/10.1128/JVI. 01563-07

18. Kimura T, Nishizawa K, Oguma A, Nishimura Y, Sakasegawa Y, Teruya K, Nishijima I, Doh-ura K (2015) Secretin receptor involvement in prion-infected cells and animals. FEBS Lett 589(15):2011-2018. https://doi.org/10.1016/j.febslet.2015.05.039

19. Mammadova N, Cassmann E, Greenlee JJ (2020) Successful transmission of the chronic wasting disease (CWD) agent to white-tailed deer by intravenous blood transfusion. Res Vet Sci 133:304-306. https://doi.org/10.1016/j.rvsc.2020.10.009

20. Hamir AN, Richt JA, Miller JM, Kunkle RA, Hall SM, Nicholson EM, O’Rourke KI, Greenlee JJ et al (2008) Experimental transmission of chronic wasting disease (CWD) of elk (Cervus elaphus nelsoni), white-tailed deer (Odocoileus virginianus), and mule deer (Odocoileus hemionus hemionus) to white-tailed deer by intracerebral route. Vet Pathol 45(3):297-306. https://doi.org/ 10.1354/vp.45-3-297

21. Moore SJ, Kunkle R, Greenlee MH, Nicholson E, Richt J, Hamir A, Waters WR, Greenlee J (2016) Horizontal transmission of chronic wasting disease in reindeer. Emerg Infect Dis 22(12):2142-2145. https://doi.org/10.3201/eid2212.160635

22. Kong Q, Zheng M, Casalone C, Qing L, Huang S, Chakraborty B, Wang P, Chen F et al (2008) Evaluation of the human transmission risk of an atypical bovine spongiform encephalopathy prion strain. J Virol 82(7):3697-3701. https://doi.org/10.1128/JVI.02561-07

23. Castilla J, Saa P, Hetz C, Soto C (2005) In vitro generation of infectious scrapie prions. Cell 121(2):195-206. https://doi.org/ 10.1016/j.cell.2005.02.011

24. Yuan J, Zhan YA, Abskharon R, Xiao X, Martinez MC, Zhou X, Kneale G, Mikol J et al (2013) Recombinant human prion protein inhibits prion propagation in vitro. Sci Rep 3:2911. https://doi. org/10.1038/srep02911

25. Choi YP, Peden AH, Groner A, Ironside JW, Head MW (2010) Distinct stability states of disease-associated human prion protein identified by conformation-dependent immunoassay. J Virol 84(22):12030-12038. https://doi.org/10.1128/JVI.01057-10

26. Peretz D, Scott MR, Groth D, Williamson RA, Burton DR, Cohen FE, Prusiner SB (2001) Strain-specified relative conformational stability of the scrapie prion protein. Protein Sci 10(4):854-863. https://doi.org/10.1110/ps.39201

27. Zou WQ, Zheng J, Gray DM, Gambetti P, Chen SG (2004) Antibody to DNA detects scrapie but not normal prion protein. Proc Natl Acad Sci USA 101(5):1380-1385. https://doi.org/10.1073/ pnas.0307825100

28. Shetty GR, Rao BL, Asha S, Wang Y, Sangappa Y (2015) Preparation and characterization of silk fibroin/hydroxypropyl methyl cellulose (HPMC) blend films. Fibers and Polymers 16(8):1734-1741

29. Gambetti P, Dong Z, Yuan J, Xiao X, Zheng M, Alshekhlee A, Castellani R, Cohen M et al (2008) A novel human disease with abnormal prion protein sensitive to protease. Ann Neurol 63(6):697-708. https://doi.org/10.1002/ana.21420

30. Zou WQ, Puoti G, Xiao X, Yuan J, Qing L, Cali I, Shimoji M, Langeveld J et al (2010) Variably protease-sensitive prionopathy: a new sporadic disease of the prion protein. Ann Neurol 68(2):162-172. https://doi.org/10.1002/ana.22094

31. Head MW, Yull HM, Ritchie DL, Langeveld JP, Fletcher NA, Knight RS, Ironside JW (2013) Variably pro-tease-sensitive prionopathy in the UK: a retrospective review 1991-2008. Brain 136(Pt4):1102-1115. https://doi.org/10.1093/brain/aws366

Publisher's Note Springer Nature remains neutral with regard to jurisdictional claims in published maps and institutional affiliations. 